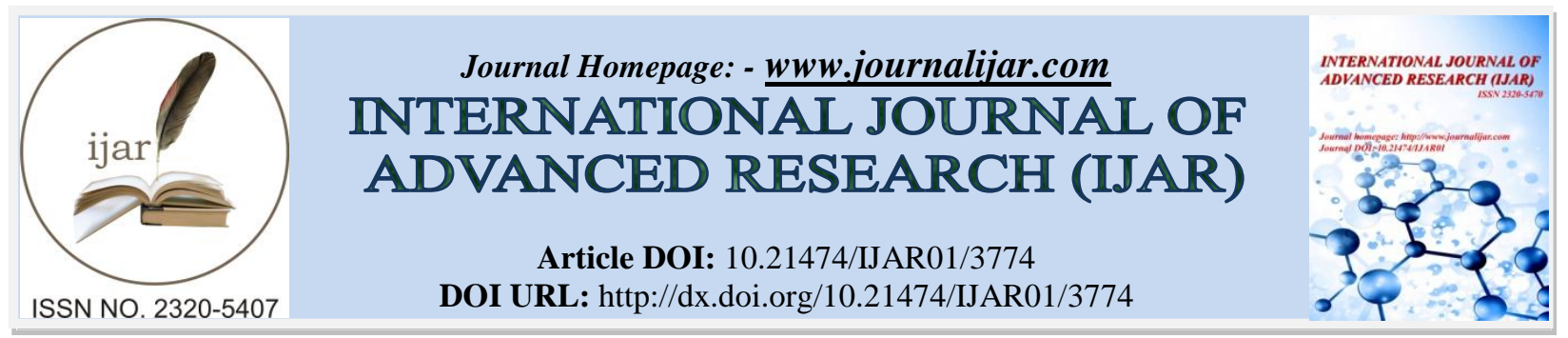

RESEARCH ARTICLE

\title{
USE OF NICKEL-TITANIUM ROTARY INSTRUMENTS AMONG DENTISTS IN CHENNAI.
}

\section{Sahil Choudhari ${ }^{1}$ and Dr. Chandana Subbarao ${ }^{2}$.}

1. 11 BDS, Department of Conservative Dentistry, Saveetha Dental College, Chennai - 600077.

2. Senior Lecturer, Department of Conservative Dentistry and Endodontics, Saveetha Dental College ,Chennai 600077

\section{Manuscript Info}

Manuscript History

Received: 01 February 2017

Final Accepted: 01 March 2017

Published: April 2017

Key words:-

NiTi, Rotary instruments, obturation, file fracture

\section{Abstract}

Objective: To assess the use of nickel-titanium (NiTi) rotary instruments among dentists in Chennai using a structured questionnaire.

Materials and Methods: A survey was conducted among dentists in Chennai using a structured questionnaire. The sample size comprised of 91 dental practitioners in Chennai.

Results: A total of 91 dental practitioners took up the survey. As many as $77(84.6 \%)$ of them use NiTi rotary instruments and $14(15.4 \%)$ of them do not use NiTi rotary instruments in their clinical practice. 28 $(30.8 \%)$ dentists believed it helped in better obturation. $42(54.5 \%)$ of the dentists experienced file fracture as the major drawback. Half of the respondents believed that the long time required to learn the technique was the reason for not using NiTi rotary instruments.

Conclusion: This survey showed the awareness of dentists about benefits of NiTi rotary instruments application comparing to traditional techniques and also the high percent usage of these instruments among dentists.

Copy Right, IJAR, 2017,. All rights reserved.

\section{Introduction:-}

The introduction of nickel-titanium (NiTi) rotary files to endodontics almost two decades ago has changed the way root canal preparations are performed, enabling more complicated root canal systems to be shaped with fewer procedural errors.

Cleaning and shaping of the root canal system is one of the main goals in endodontics which can be carried out using different systems and techniques. To reach this aim, stainless steel hand instruments have been traditionally applied. Lack of flexibility of instruments causes errors during endodontic treatments which lead to decreased success rate. [1] After introducing rotary nickel-titanium (NiTi), their usage became popular. NiTi instruments super elasticity along with their advanced design made them favourable for effective and safe instrumentation of narrow and curved root canals using low torque handpieces. The ability of some NiTi rotary systems in maintaining the root canal curvature has been studied. [2]

Nickel-titanium alloy was developed in the 1960s, initially for military purposes, but it soon became apparent that NiTi was also useful for other applications, such as orthodontic wires and dental burs. K-type root canal files were made of NiTi and tested extensively. The first NiTi rotary files appeared on the market around 1993. These early rotary files were designed with cross-sections that did not have cutting edges but rather broad radial lands. [3][4] 
The advent of nickel-titanium alloys allowed the design and development of rotary instruments with 360-degree rotation, to be used specifically in curved canals. This contributed to a more rapid preparation process and to a lower degree of stress for both the dentist and the patient. Rotary files may fracture rather unexpectedly or create procedural errors. Therefore, knowledge of several clinical golden rules and basic understanding of metallurgical properties of NiTi rotary files are critical for successful use. [5][6]

In spite of the many advantages described in the literature for nickel-titanium endodontic instruments, no study so far has provided information on the use of this new technology in clinical practice in Chennai. Therefore, we conducted a survey with dental practitioners in Chennai, to assess the use of nickel-titanium rotary instruments and to identify possible reasons for using, not using or interrupting the use of these instruments during the preparation of root canals.

\section{Materials and methods:-}

Ninety-one dental practitioners residing in Chennai practicing endodontic procedures took up the survey. A questionnaire was used for collecting information covering demographics, the use or disuse of rotary instruments and the various reasons for its use or disuse.

All the questionnaires were evaluated and the answers to each question were analyzed and tabulated to allow individual comparison of data. Results were submitted to the analysis of frequency measures and plotted in piecharts and tables so as to facilitate data interpretation.

\section{Results:-}

\section{General and demographical data:-}

A total of 91 dental practitioners took up the survey. Of the respondents who took up the survey, 35 (38.48\%) dentists were below 30 years of age, $28(30.76 \%)$ dentists were between $30-40$ years of age and $28(30.76 \%)$ dentists were above 40 years of age. The frequency of distribution based on gender indicated that $49(53.8 \%)$ were females and $42(46.2 \%)$ were males. $28(30.8 \%)$ of the dentists had clinical experience of lesser than 5 years, $35(38.5 \%)$ dentists with experience between 5-10 years and 28 (30.8\%) dentists with over 10 years of clinical experience.

SEX
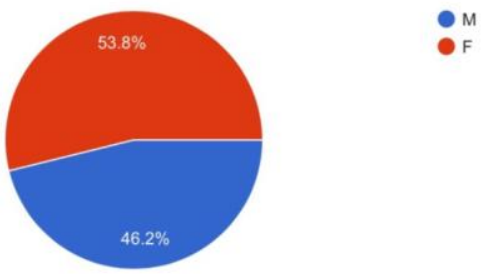

YEARS OF EXPERIENCE AS A CLINICIAN
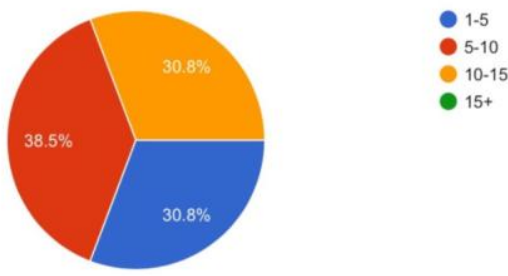

Frequency of use of niti rotary instruments:-

Among the 91 dental practitioners who took up the survey, 35 (38.5\%) of them use rotary endodontics for over 5 years and $56(61.5 \%)$ use rotary endodontics for lesser than 5 years. As many as 77 (84.6\%) of them use NiTi rotary 
instruments and $14(15.4 \%)$ of them do not use NiTi rotary instruments in their clinical practice. Almost all respondents believed that using rotary instruments makes the procedure easier.

\section{YEARS OF PRACTICE OF USING ROTARY ENDODONTICS}
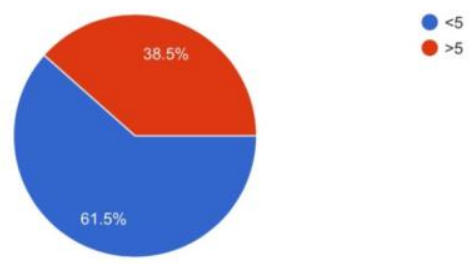

DO YOU USE NICKEL-TITANIUM ROTARY INSTRUMENTS?

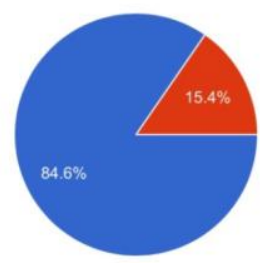

Yes

No

\section{Advantages and disadvantages associated with niti rotary instruments:-}

$28(30.8 \%)$ dentists believed that using rotary instruments helped in faster instrumentation. Another 28 (30.8\%) dentists believed it helped in better obturation. 14 (15.4\%) dentist believed it helped in maintaining the canal curvature and working length.

$42(54.5 \%)$ of the dentists experienced file fracture as the major drawback. Others faced problems such as apical deviation or excess dentin removal.

PROBLEMS EXPERIENCED DURING USE OF NICKEL-TITANIUM ROTARY INSTRUMENTS

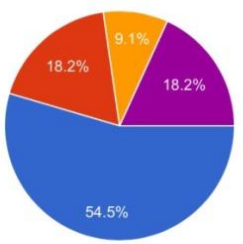

- File fracture

- Apical deviation

- Excess dentin removal

Root canal leakage

ADVANTAGES ASSOCIATED WITH ROTARY INSTRUMENTS

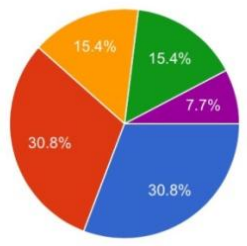

Faster instrumentation

- Easier obturation

Maintenance of canal curvature

Maintenance of working length

- Other reasons

Reason for not using niti rotary instruments:-

Half of the respondents believed that the long time required to learn the technique was the reason for not using NiTi rotary instruments. Also, the cost and difficult to use such instruments were the other reasons for not using NiTi instruments. 


\section{IN CASE YOU DO NOT USE NICKEL-TITANIUM ROTARY INSTRUMENTS, REASON?}
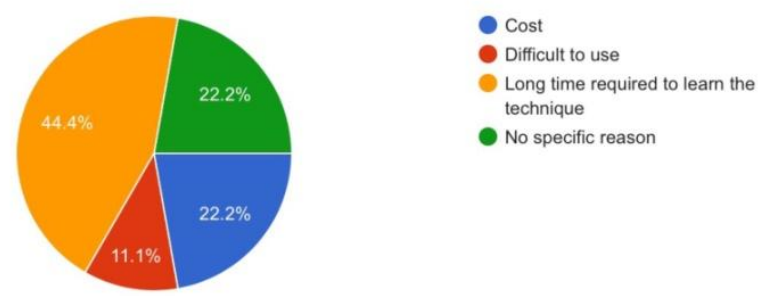

\section{Discussion:-}

The results of this study showed that $84.6 \%$ of respondent used NiTi rotary instruments. Our findings were in consistent with some previous studies : $22 \%$ of general dentists and $64 \%$ of endodontists in an Australian study, [7] approximately $70 \%$ of general dentists and almost $83 \%$ of endodontists in a study performed in UK [8][9] as well as $77 \%$ of the Swedish general dentists who participated in an endodontics educational program [10] have mentioned that they used NiTi rotary instruments.

Dentists experienced fracture of files as the major drawback. In a previous report, Guelzow et al. [11] showed the most file fracture was at size 30. Di Fiore et al. [12] reported the tip sizes of the instruments that fractured ranged from 20 to 40 .

In our study, $28(30.8 \%)$ dentists believed that using rotary instruments helped in faster instrumentation. Another 28 $(30.8 \%)$ dentists believed it helped in better obturation. $14(15.4 \%)$ dentists believed it helped in maintaining the canal curvature and working length. In comparison to a study by Parashos and Messer, [7] faster canal preparation (80\%), maintaining canal curvature (73\%) and easier final canal obturation (72\%) were identified as the most important advantages. However, in a study by Barbakow and Lutz, [13] safety (82\%), dentists and patients' comfort (76\%) and faster canal preparation (54\%) and in a study by Bjourndal and Reit, [14] faster canal preparation, consequently decreased visit sessions and treatment length were the most reported advantages. Koch et al, [10] reported greater root filling quality, less physically tiring technique for practitioners along with fast and easy procedures as advantages. Because of shorter treatment length, most patients are likely to refer to endodontists in comparison to general dentists.

One of the main obstacles to use NiTi instruments by dentists lies in unbelieving in new techniques. Along with the latter, beliefs that NiTi rotary instruments are prone to fracture and dealing with them is complicated, are of causes that dentists do not use these instruments routinely. In addition, a large scale of dentists believe that it takes them too much time to learn how to work with NiTi rotary instruments, which might reveal that they are widely under the influence of their senior colleagues. In our study, reasons for not using NiTi instruments appear the same as the ones which have been previously reported. The most important reason for not using NiTi instruments seems to be lack of adequate education. [4][14]

\section{Conclusion:-}

Dentists are familiar with limitations of NiTi instruments and techniques. Moreover, they are increasing efficacy of their practice by using these appliances. This study showed the awareness of dentists about benefits of NiTi rotary instruments application comparing to traditional techniques and also the high percent usage of these instruments among dentists. Results of this questionnaire have demonstrated that dentists and dental students need more training and more comprehensive education regarding new techniques and methods. 


\section{References:-}

1. Coleman CL, Svec TA. Analysis of Ni-Ti versus stainless steel instrumentation in resin simulated canals. J Endod. 1997;23(4):232-5.

2. Nivesh Krishna R, Pradeep S. Recent diagnostic aids in endodontics : a review. IJPCR. 2016;8(8): 1159-1162.

3. Teresa Rao, Prassana Neelakantan. Three dimensional imaging modalities in endodontics. Imaging Sci Dent. 2014 Sept ;44(3):177-183

4. P. Neelakantan, C.Q. Cheng, R. Mohanraj, P. Sriraman, C. Subbarao, S. Sharma. Antibiofilm activity of three irrigation protocols activated by ultrasonic, diode laser or Er:YAG laser in vitro. IEJ. 2015;48;6:602-610.

5. Mandel E, Adib-Yazdi M, Benhamou L, Lachkar T, Mesgouez C, Sobel M. Rotary Ni-Ti proile systems for preparing curved canals in resin blocks: inluence of operator on instrument breakage. Int Endod J. 1999;32(6):436-43.

6. Umaiyal M. Pooja. Awareness about root canal treatment among people. RJPT. 2016;9;7:779-781.

7. Parashos P, Messer HH. Questionnaire survey on the use of rotary nickel-titanium endodontic instruments by Australian dentists. Int Endod J 2004;37:249-59.

8. Madarati AA, Watts DC, Qualtrough AJ. Opinions and attitudes of endodontists and general dental practitioners in the UK towards the intracanal fracture of endodontic instruments: part 1. Int Endod J 2008;41:693-701. Epub 2008 Jun 28.

9. Madarati AA, Watts DC, Qualtrough AJ. Opinions and attitudes of endodontists and general dental practitioners in the UK towards the intracanal fracture of endodontic instruments. Part 2. Int Endod J 2008;41:1079-87.

10. Koch M, Eriksson HG, Axelsson S, Tegelberg A. Effect of educational intervention on adoption of new endodontic technology by general dental practitioners: a questionnaire survey. Int Endod J 2009;42:313-21. Epub 2009 Feb 7.

11. Guelzow A, Stamm O, Martus P, Kielbassa AM. Comparative study of six rotary nickel-titanium systems and hand instrumentation for root canal preparation. Int Endod J 2005;38:743-52.

12. Di Fiore PM, Genov KA, Komaroff E, Li Y, Lin L. Nickel-titanium rotary instrument fracture: a clinical practice assessment. Int Endod J 2006;39:700-8.

13. Barbakow F, Lutz F. The 'Lightspeed' preparation technique evaluated by Swiss clinicians after attending continuing education courses. Int Endod J 1997;30:46-50.

14. Bjørndal L, Reit C. The adoption of new endodontic technology amongst Danish general dental practitioners. Int Endod J 2005;38:52-8. 